\title{
Summer undergraduate nursing research experience: Implementing a mentor-based research program for minority nursing undergraduates
}

\author{
Darpan I. Patel ${ }^{* 1,3}$, Vanessa Meling ${ }^{1,2}$, Afsha Somani ${ }^{1}$, Danila Larrotta ${ }^{1}$, David A. Byrd ${ }^{1,2}$ \\ ${ }^{1}$ School of Nursing, University of Texas Health Science Center at San Antonio, San Antonio, United States \\ ${ }^{2}$ Student Success Center, School of Nursing, University of Texas Health Science Center at San Antonio, San Antonio, United \\ States \\ ${ }^{3}$ Cancer Therapy and Research Center, University of Texas Health Science Center at San Antonio, San Antonio, United States
}

Received: November 28, 2016

DOI: $10.5430 /$ jnep.v7n7p37
Accepted: January 22, $2017 \quad$ Online Published: February 14, 2017

URL: http://dx.doi.org/10.5430/jnep.v7n7p37

\begin{abstract}
The Summer Undergraduate Nursing Research Immersion Experience (SUNRISE) program was developed to provide opportunities for eligible underrepresented/underserved (UR/US) undergraduate nursing students to participate in a semi-structured summer research experience. First year undergraduate nursing students enrolled full-time in the Bachelor of Science in Nursing program were eligible to participate in SUNRISE. Significant improvements were seen in the student's self-efficacy as scientists (pre: $4.4 \pm 0.27$; post: $4.6 \pm 0.17$ ) and the student's perception of their role in research. Using a mentor-based approach, UR/US students were given one-on-one training that is often lacking in nursing programs. Though only in its first year, preliminary data suggest that the SUNRISE program can impact UR/US student's sense of scientific efficacy preparing these students for success beyond nursing school.
\end{abstract}

Key Words: Undergraduate research, Nursing, sciences, technology, engineering and math (STEM), Underrepresented minority students

\section{INTRODUCTION}

Baccalaureate nursing student success - as with most other higher education curricula - is often predicated upon the relationships that are fostered between the students and their environment. Astin's (1993) Input-Environment-Outcome Model continues to provide a relevant description of the confluence of student performance with the campus environment. ${ }^{[1]}$ His research demonstrated that the more integrated students are into their academic environment, the more likely they are to succeed. These relationships are increasingly important for historically underrepresented students where mentoring by faculty with whom the students can relate can enhance persistence and mitigate micro-aggressions often experienced by these vulnerable subpopulations. ${ }^{[2]}$ Beauvais, Stewart, DeNisco and Beauvias (2013) discovered that there are factors that can be correlated to the success of nursing students. ${ }^{[3]}$ Researchers have also identified that the non-cognitive barriers (i.e., financial, etc.) that often led to increased attrition for historically under-represented nursing students could be overcome through increased support programs that enhance integration into both the academic program and the nursing profession coupled with mentoring by

*Correspondence: Darpan I. Patel; Email: PatelD7@uthscsa.edu; Address: School of Nursing, University of Texas Health Science Center at San Antonio, San Antonio, United States. 
racially or ethnically underrepresented faculty members. ${ }^{[4,5]}$

In the fall of 2015, the University of Texas Health Science Center at San Antonio School of Nursing was awarded a US Department of Education Title V Developing HispanicServing Institutions Program grant that provided approximately $\$ 2.5$ million in funds over five years. The grant entitled Realce: Academic Enhancement for South Texas Nurses, provides a two-pronged approach to address specific problems identified in the school by developing and improving academic support programs for at-risk and/or Hispanic learners (Activity I) and by providing narrowly-tailored faculty development activities and developing a new undergraduate research program entitled the Summer Undergraduate Nursing Research Immersion Experience (SUNRISE) that connects Hispanic, first-generation, low-income, and at-risk students with faculty engaged in ground breaking research in the field of nursing (Activity II).

The project deliverables under Activity I include academic support, academic coaching, student engagement, and technology support. The academic support component exists to enhance student learning through personal tutoring and supplemental instruction, measured by student performance in nursing courses and by first-time pass rates on the NCLEX$\mathrm{RN} \cap$ Licensure Exam. The academic coaching program aims to enhance academic skills through academic coaches who focus on non-cognitive skills such as time management, study skills, and critical thinking skill development. The student engagement programs are delivered through a peer mentoring program, family engagement event, and financial literacy seminars. The technology support funds are used for early identification of at-risk students to make informed decisions and provide targeted interventions and resources for our nursing students.

The project deliverables under Activity II include the development and implementation of an undergraduate research program to increase undergraduates' co-authorship and submission of an abstract and/or manuscript for publication in the scientific literature. Finally, the project allows for faculty development workshops that support SON faculty to learn from nationally recognized curriculum and instruction experts on topics such as course curriculum development, flipped classroom teaching, and integration of app based technologies.

Key measures of success for the grant include a) the improvement of the first-time pass rate on the NCLEX-RN $R$ examination by SON graduates, b) the increase in research productivity by undergraduate students, and c) the improvement in cultural competence and instructional ability by SON faculty throughout the undergraduate curriculum. The Re- alce project serves to enhance the student learning experience with academic supports, enhance faculty competencies in their ability to teach a new generation of diverse students, and ultimately enhance the School of Nursing to better provide for the healthcare needs of South Texas and the Rio Grande Border region.

Undergraduate research experiences (URE) have been reported to aide in undergraduate success, improve preparation of the next generation of scientists and increase the enrollment and retention of underrepresented minorities in graduate education. ${ }^{[6-9]}$ Undergraduate research has been identified by the Association of American Colleges and Universities as a high-impact educational practice that engages students in behaviors that serve to gain knowledge and skillsets that will allow students to more successfully navigate future societal challenges. ${ }^{[10,11]}$ Typically, research experience is done through an undergraduate research experience with a mentor-mentee dyad or through course-based research experiences. ${ }^{[12]}$ While each of these two forms of research experience provides valuable skills, it is the one-on-one interaction between the student and the research mentor that literature has shown to be valuable in guiding students towards graduate education. ${ }^{[13]}$ UREs in the area of nursing, particularly in colleges and universities that are focused on increasing diversity, have the potential to facilitate the students' understanding of how the science that underpins the discipline of nursing is discovered and subsequently translated into practice.

In recent years, the National Institutes of Health and other federal government agencies have invested millions of dollars annually to fund programs whose primary goal is to support underrepresented students in obtaining post-secondary degrees in the sciences. ${ }^{[14]}$ The tangible outcome of UREs is to build a successful pool of students who are more likely to enroll in graduate school and successfully complete the objectives of the government programs. Our program, SUNRISE, provides opportunities for eligible undergraduate nursing students to participate in a semi-structured summer research program mentored by faculty members from the School of Nursing. Just after the first year of this program, students have boosted their efficacy as scientists and have become encultured in research through laboratory-based and communitybased programs of science. Though the outcomes of this program are preliminary at best, the foundation for success has been established with positive signs for future cohorts that participate in the SUNRISE program.

\section{Methods}

Using the knowledge integration framework, ${ }^{[15]}$ the goals of SUNRISE are to 1) Develop skills to conduct research from 
the origination of ideas to analysis and reflection of study results; 2) Expand knowledge of the phenomena of interest; 3) Understand the nature of science; and 4) Develop an identity as a nurse scientist and nurse researcher. Outcomes from this program are based on the student participants' research output and their long-term goals of authorship and

application for graduate education in the biomedical sciences (see Figure 1; Logic Model for SUNRISE). The SUNRISE program also aims to boost student and faculty engagement, a significant problem in nursing schools. A mixed-methods approach was used to evaluate the effectiveness of the SUNRISE program.
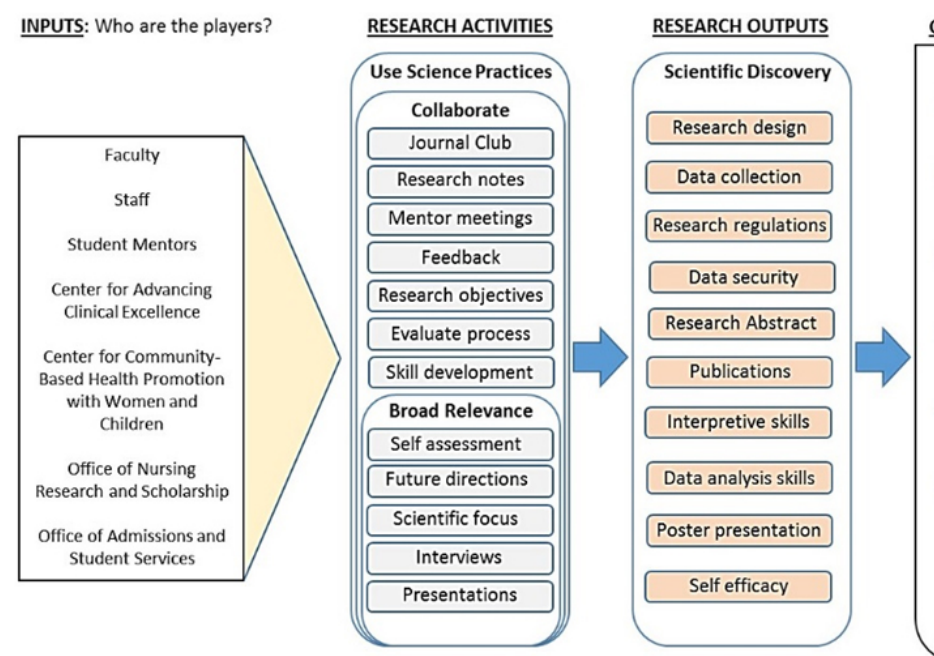

OUTCOMES: Short to Lon

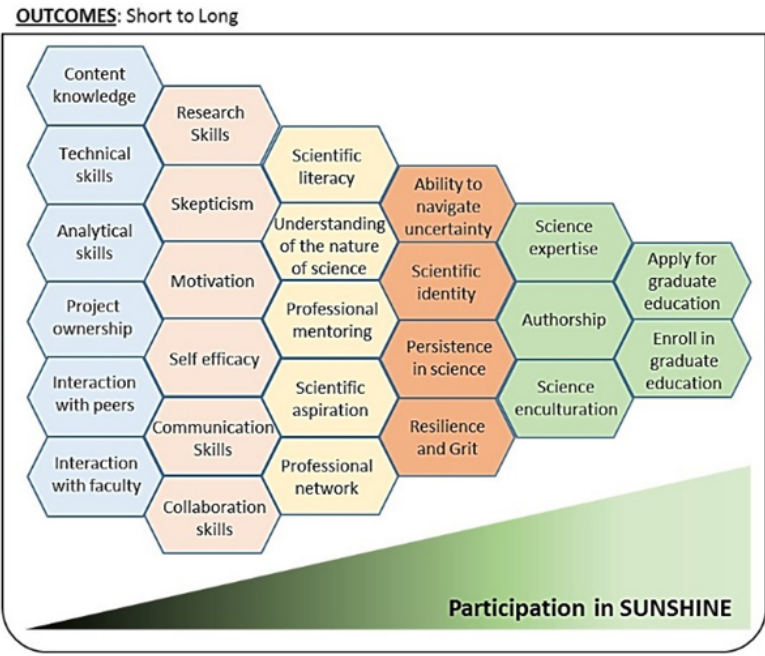

\section{ASSUMPTIONS}

Undergraduates will increase knowledge of the scientific process for nursing research

Collaborative partnerships will create a sense of self-worth and self-efficacy in nursing students to participate in SUNSHINE.

- Participation in the SUNSHINE will increase application and acceptance rates of underrepresented minorities into graduate education.

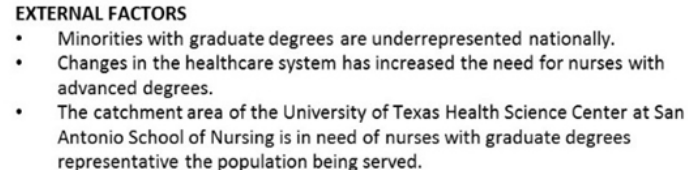

XTERNAL FACTORS advanced degrees.

Antonio School of Nursing is in need of nurses with graduate degrees representative the population being served.

Figure 1. SUNRISE Logic Model

The SUNRISE Logic Model will help guide the evaluation of the summer undergraduate research experience. This model identifies the individuals that play a critical role in the success of the program, the research activities that will guide nurse scientist development, the expected contributions to science our students will make (research outputs), and the expected outcomes from the SUNRISE program. Outcomes are ordered left to right according to when students might be able to demonstrate the outcomes through their participation in the SUNRISE program.

\begin{tabular}{|c|c|c|}
\hline Selection Criteria & Curriculum & Mentoring \\
\hline $\begin{array}{l}\text { Competitive application } \\
\text { process } \\
\text { Interview with SUNRISE } \\
\text { Director and mentors } \\
\text { Likelihood for success } \\
\text { Status representative of } \\
\text { nursing school population } \\
\text { GPA }\end{array}$ & $\begin{array}{l}\text { Apprenticeship model } \\
\text { Observe mentor's } \\
\text { research program, learn } \\
\text { data collection, lab } \\
\text { techniques, attend PI's } \\
\text { lab meetings } \\
\text { Journal Club / Journaling } \\
\text { Experiences } \\
\text { Poster presentation at } \\
\text { conference }\end{array}$ & $\begin{array}{l}\text { Principal investigator, } \\
\text { graduate students, peers } \\
\text { Guidance from the } \\
\text { Director of SUNRISE, } \\
\text { Office of Admissions and } \\
\text { Student Success, Student } \\
\text { Success Center } \\
\text { Exit interview to improve } \\
\text { the SUNRISE program }\end{array}$ \\
\hline
\end{tabular}

Figure 2. Key SUNRISE Characteristics

Participants in the SUNRISE program will be led by mentors that share a similar research interest to that of the student. Through a competitive application process, students will be matched with mentors, participate in program activities and produce tangible outcomes.

\subsection{SUNRISE application process}

Enrollment into the SUNRISE program was done through an application based process and interview of first year under-

Published by Sciedu Press graduate nursing students enrolled full time in the traditional Bachelor of Science in Nursing (BSN) program (see Figure 2; SUNRISE Curriculum). A two-summer commitment was 
required of students to take full advantage of the SUNRISE program. During the application process, students identified 2-3 mentors with whom they would be interested in working with. The SUNRISE team interviewed the students and the mentors identified in the application. Acceptance into the SUNRISE program was based on a cumulative assessment of eligibility, potential for success, goodness of fit into the mentor's research and mentor's willingness to supervise.

\subsection{Journal club}

Each week, students participated in a one-hour journal club. The journal club served as an education intervention to improve reading skills, content knowledge, statistical analysis skills, interpretation skills and the use of medical terminology in research. Participation in the journal club supplemented their tailored research projects providing the students with experience in critically appraisaling the literature, understanding the limitations and applications of research into practice, recognizing and understanding basic study design, becoming familiar with basic statistical tests, gaining skills in the interpretation of data, and improving skills related to oral and written presentations. The faculty from the School of Nursing were also featured during the weekly journal club through a "Faculty Spotlight" session. The culminating experience of the journal club was a 15-minute presentation by each student on their research project to the other SUNRISE students, their mentors and the SUNRISE project team.

\subsection{Weekly journaling}

Students were asked to keep journals to reflect on the summer experience. Journal reflections have been reported to promote the identity of undergraduate students as scientists and help connect the research experience to what students' thoughts are of themselves as scientists. ${ }^{[16]}$ In addition to the traditional laboratory notebook, completion of the reflective journals is a key component of the SUNRISE program to help nursing students create an identity as a nurse scientist.

\subsection{Entry and exit interviews}

Semi-structured interviews were conducted with each participant before and after the first 8-week summer research session. Each interview lasted approximately 30 minutes and covered topics related to students' role in research, their perception of nursing research, expectations of the SUNRISE program and anticipated benefits of the program.

The entry interviews asked the students to define research in their own words, their perceptions of the research environment in the School of Nursing, prior experiences in research, their understanding of the student's role in research and questions about their understanding of the SUNRISE program and what they hope to get out of this experience.
The exit interviews, conducted during the last week of the summer, asked the scholars to reflect back on their definition of research and their perceptions now of what academic researchers and student research assistants are and are not. Students were asked about their perceptions as a scientist and their engagement in the research process. Students were also asked evaluation based questions about SUNRISE.

\subsection{Pre-post assessments}

Quantitative evaluation of the SUNRISE program was conducted through surveys administered to both students and mentors before and after the summer program as described by Lopatto, ${ }^{[17]}$ Kardash $^{[18]}$ and Adedokun. ${ }^{[16]}$ In addition to general demographic information, the survey asked questions regarding the student's plans for education beyond the undergraduate degree, how the research experience influenced the student's plans for postgraduate education and gains made during the undergraduate research experience (i.e. understanding of the research process, mastery of lab techniques, interpretation of scientific literature, skills in scientific writing and presentation, translation to nursing, etc.).

A thirty-six question survey, using a 5-point Likert scale, was administered that covered 8 subscales: scientific aspirations, self-efficacy as a scientist, inter-professional relationships, research skills-communication, research skills-data, research skills-literature and research skills-methods. Additionally, students were asked about their interest in graduate school and the burden of a summer research program.

\subsection{Data analysis}

Qualitative review of the interview transcripts and weekly journal entries were conducted independently by two of the co-authors and verified by a third. Basic content analysis was used to identify key themes from the transcribed interview. A paired t-test was performed on the survey data with descriptive statistics reported (mean \pm standard deviation). Significance was set at $p \leq .05$.

\section{RESULTS}

The apprenticeship model implemented in the SUNRISE program aims to break down the perceived barriers between underrepresented students and nursing school faculty. Previous reports have suggested that integrating underrepresented minorities in a structured program boosts likelihood for success. Further, participating in undergraduate research programs provides a significant opportunity for underrepresented minorities to be mentored one-on-one in a rigorous, scientifically based research programs and provided the opportunity to contribute in the dissemination of research through abstract and manuscript publications and presentations at

ISSN 1925-4040 E-ISSN 1925-4059 
national conferences.

\subsection{Participant demographics and participation rates}

In total, six nursing students applied for the SUNRISE program and four were selected. The four participants in the first cohort of the SUNRISE program came from varying ethnic backgrounds, specifically, African-America, Filipino, Hispanic White and Non-Hispanic White. Only, 1 of the 4 students held a bachelor's degree (BS in biology). Participants were equally distributed based on sex and all participants were between 21-26 years of age.

Student participation in the journal club was extremely favorable with $96 \%$ attendance in the weekly meetings. Also, all four of the SUNRISE students successfully completely $100 \%$ of the online journal entries.

\subsection{Qualitative outcomes}

The entry interviews revealed that the students were unaware of nursing research and research opportunities in the SON. The students' perception of research was limited. The students viewed SUNRISE as an opportunity to improve oral and written skills while evolving research skills to further their development as nursing scientists.

The exit interviews revealed that the program changed the way students define research, shifting from an operational definition to a more contextual definition. Each of the 4 SUNRISE scholars defined research using textbook style definition with examples given using the scientific method for research, the quest for new knowledge and answering a research question using structured protocols. However, upon completing the first 8-week session of SUNRISE, the defini- tion of research shifted into a contextual definition, including personnel management, dissemination strategies, protocol development, and the structure and process of conducting research. The students' perception of their role in research also shifted from a supportive role to a project lead role. Other benefits students recognized were improved written and oral communication skills, appraisal of the literature, and a sense of community amongst the SUNRISE participants.

Furthermore, the students' weekly journaling revealed improvements in SUNRISE outcomes such as self-efficacy as scientists, aspiration to pursue research, inter-professional relationships, and understanding of the scientific process.

\subsection{Quantitative outcomes}

Table 1 presents the survey outcomes for the Year 1 cohort of the SUNRISE program $(n=4)$. Of the 8 subscales calculated, all but 2 had positive improvements following the 8 -week program. Significant improvements were seen in the student's self-efficacy as a scientist $(p=.05)$. The greatest decrease was seen in the research skills-data subscale. The $14 \%$ decrease in score for research data skills could be an indication that after participating in the mentor-based research program, the student's research skills related to data collection, analysis and interpretation needed improvement; a possible outcome of their improved understanding of the research process. Further, students felt that the summer research program held no additional burden on their schooling. Each student also indicated they had high aspirations of applying for graduate school. Programs included Doctorate of Philosophy, Masters of Science in Nursing, and Medical Doctorate.

Table 1. Pre-post survey results on outcome measures of Sunrise

\begin{tabular}{llll}
\hline Subscales & Pre & Post & $\Delta$ \\
\hline Scientific Aspiration & $4.5 \pm 1.18$ & $4.9 \pm 1.74$ & 0.09 \\
Self-Efficacy as a Scientist* & $4.4 \pm 0.27$ & $4.6 \pm 0.17$ & 0.05 \\
Interprofessional Relationships & $4.0 \pm 1.22$ & $3.9 \pm 0.75$ & -0.03 \\
Research Skill-Communication & $3.5 \pm 0.44$ & $3.5 \pm 0.23$ & 0.00 \\
Research Skill-Data & $4.3 \pm 0.35$ & $3.7 \pm 1.0$ & -0.14 \\
Research Skill-Lab & $3.9 \pm 0.25$ & $4.0 \pm 0.71$ & 0.03 \\
Research Skill-Literature & $3.9 \pm 0.48$ & $4.1 \pm 0.48$ & 0.05 \\
Research Skill-Methods & $4.1 \pm 0.30$ & $4.2 \pm 0.28$ & 0.02 \\
\hline
\end{tabular}

*Significant at $p=.05$

\section{Discussion}

Undergraduate research experiences have been reported to aide in undergraduate student success, improved preparation of next generation scientists, and increased application, enrollment and retention of underrepresented minorities in

Published by Sciedu Press graduate education. In many sciences, technology, engineering and math (STEM) based programs, UREs are valuable in preparing students for work outside of the classroom and preparation for graduate school. However, the majority of undergraduate nursing programs have fallen short in 
implementing mentor-based research programs, though the literature supports UREs in career decision-making and active learning. ${ }^{[19]}$ This experience is doubly beneficial for underrepresented minorities because they are able to build relationships with faculty with whom the students can relate to. This mentor-mentee relationship can enhance persistence and retain these students, who are often first in their family to attend college. SUNRISE was implemented to give underrepresented students the opportunity to engage in one-on-one training that is often lacking in nursing programs. Though only in its first year, the SUNRISE program was capable of making distinct improvements in underrepresented students' sense of scientific efficacy and contributions to science, boosting potential for success in nursing school and beyond. Although preliminary, the results of our first year evaluation of the SUNRISE program support previous findings regarding the benefits of undergraduate research participation. ${ }^{[13,17,20,21]}$

\subsection{Impact on underrepresented minorities}

A barrier to student engagement in research programs in our school was the perceived separation between faculty and students (unpublished data). Particularly with underrepresented students, there is a sense of disengagement between $\mathrm{PhD}$ prepared faculty and students enrolled in their courses based on hierarchy and stature. This can lead to mistrust between faculty and students and can promote an environment of micro-aggressions often experienced by these vulnerable subpopulations. For example, 2 of the 4 students in this cohort of SUNRISE indicated a feeling of discomfort in completing the weekly journal activity because they were unsure of who was going to read them and how their notes would be used, though they were informed at the beginning of the program that the journaling activity was a way for the project team to gauge their growth as a scientist and that only the individuals doing the qualitative review would have access.

Through the first 8 weeks of the program, the students improved their self-efficacy as scientists, which can significantly contribute to their success in nursing school. By improving self-efficacy in our cohort, the skills associated with scientific independence, namely, communication skills, literature skills and scientific methods saw improvements as well. This can be greatly beneficial to minority students. Underrepresented minorities, researchers have found, often face non-cognitive barriers that often led to increased attrition particularly in STEM based programs, nursing students included. These barriers can be overcome through the development of skills as a result of active participation in undergraduate research programs. Past reports have examined the effects of UREs and concluded that these programs represent an important catalyst to facilitate learning and success of underrepresented minorities in STEM education. ${ }^{[19]}$

\subsection{Lessons learned and future directions}

During the exit interviews, the SUNRISE scholars provided valuable feedback that will help us improve the program in the coming years. One specific recommendation that will be implemented is an onboarding workshop to orient the students to the SUNRISE program, program calendar, topics for journal clubs, lab orientation, and library orientation. We're hopeful that by adding this onboarding session during the first days of the student's participation in the SUNRISE program will facilitate their enrollment into the program.

We will also modify our weekly online journals to make them available at the beginning of every week and allow students to be able to access their journals for the entire week rather than the last few days of the week as we had originally done. The students indicated that by limiting the journal entries to the final days of the week, it took more time for them to be able to reflect on their feelings and perceptions of the activities they did at the beginning of the week. By keeping the online journal accessible for the entire week, students can immediately document their reflections on the day's activities. Given that journaling provided valuable information to our program, it is a highly reliable form of program evaluation and gives the students the ability to review their development as scientists across time, we felt this minor modification to our online module to be a valuable lesson learned.

The small number of applicants to the SUNRISE program was a concern in the first year of the program. Though an information session was successful in bringing in approximately 20 students, enthusiasm in the program was modest with only 6 individuals applying. A modified recruitment plan is being developed, in collaboration with various ethnic and international student-nursing associations on campus to boost recruitment of underrepresented minorities to apply to the program.

One of the biggest deficits that many students face when beginning a nursing school program is the ability to write scientifically. ${ }^{[22]}$ This was no exception for our SUNRISE students. Though half of this first cohort had previous research experience and all students in SUNRISE had high grade point averages coming into the nursing program and maintain high averages in the BSN program, scientific writing still needs to be developed. In order to address the underperformance in writing skills among nursing students, Derouin et al. (2015) found workshops to be effective in preparing nursing students for publications and to improve writing skills. ${ }^{[23]}$ Therefore, to boost their scientific writing 
skills, a writing workshop will be scheduled during the first weeks of the summer for new cohorts that begin the program. In this workshop, we plan to discuss tips for starting and organizing a paper, American Psychological Association (APA) formatting and citations, tips for better scholarly writing and reviewing common mistakes made in scholarly writing. Although the findings of this study are important, we interpret the results with some caution. First, the small sample, limited by a single cohort preliminary analysis, leaves speculation on the effectiveness of the SUNRISE program. Further, students that participated in the SUNRISE program are high achieving students with grade point averages and elevated self-worth and efficacy. This was evident in the baseline survey response for research skills. The impact of SUNRISE

\section{REFERENCES}

[1] Astin, A.W., What matters in college?: Four critical years revisited. Vol. 1. 1993: Jossey-Bass San Francisco.

[2] Smith B. Mentoring at-risk students through the hidden curriculum of higher education. 2013: Lexington Books.

[3] Beauvais AM, et al. Factors related to academic success among nursing students: a descriptive correlational research study. Nurse Education Today. 2014; 34(6): 918-923. PMid:24380623 https: //doi.org/10.1016/j.nedt.2013.12.005

[4] Loftin C, et al. Diversity in Texas nursing programs: A study of the relationship between supportive characteristics and graduation of Hispanic and other underrepresented minority nursing students. Hispanic Health Care International. 2012; 10(4): 159-167. https://doi.org/10.1891/1540-4153.10.4.159

[5] Melillo KD, et al. BRING DIVERSITY TO NURSING: RECRUITMENT, RETENTION, AND GRADUATION OF NURSING STUDENTS. Journal of Cultural Diversity. 2013; 20(2).

[6] Graham MJ, et al. Increasing persistence of college students in STEM. Science. 2013; 341(6153): 1455-1456. PMid:24072909 https://doi.org/10.1126/science.1240487

[7] Kuh GD, et al. Student success in college: Creating conditions that matter. 2011: John Wiley \& Sons.

[8] Pascarella ET, Terenzini PT. How college affects students: A third decade of research. San Francisco: Jossey-Bass. 2005.

[9] Woodin T, Carter VC, Fletcher L. Vision and change in biology undergraduate education, a call for action-initial responses. CBELife Sciences Education. 2010; 9(2): 71-73. PMid:20516350 https : //doi.org/10.1187/cbe.10-03-0044

[10] Kuh GD. Excerpt from high-impact educational practices: What they are, who has access to them, and why they matter. Association of American Colleges and Universities. 2008.

[11] Brownell JE, Swaner LE. Five high-impact practices: Research on learning outcomes, completion and quality. 2010: Association of American Colleges and Universities.

[12] Auchincloss LC, et al. Assessment of course-based undergraduate research experiences: a meeting report. 2014. Am Soc Cell Biol.

[13] Eagan MK, et al. Making a difference in science education the impact of undergraduate research programs. American Educational on at-risk students must be evaluated. Notwithstanding these limitations, this study contributes to research and evaluation studies of the outcomes of undergraduate research programs in nursing. This study also outlines a model that can provide a framework for developing a research program in traditional undergraduate nursing programs of the possible relationships between UREs and nursing student success, particularly as it relates to underrepresented minorities.

\section{ACKNOWLEDGEMENTS}

Funding for this project was provided by the US Department of Education Title V Grant (P031S150048).

\section{CONFLicts OF InTEREST Disclosure}

The authors declare that there is no conflict of interest.
Research Journal. 2013; 50(4): 683-713. PMid:25190821 https: //doi.org/10.3102/0002831213482038

[14] Thiry H, et al. The benefits of multi-year research experiences: differences in novice and experienced students' reported gains from undergraduate research. CBE-Life Sciences Education. 2012; 11(3): 260-272. PMid:22949423 https://doi.org/10.1187/cbe.11 $-11-0098$

[15] Linn MC, Eylon BS, Davis AE. The knowledge integration perspective on learning. Internet Environments for Science Education. 2004; 29-46.

[16] Adedokun OA, et al. Research skills and STEM undergraduate research students' aspirations for research careers: Mediating effects of research self-efficacy. Journal of Research in Science Teaching. 2013; 50(8): 940-951. https://doi.org/10.1002/tea. 21102

[17] Lopatto D. Survey of undergraduate research experiences (SURE): First findings. Cell Biology Education. 2004; 3(4): 270-277. PMid:15592600 https : //doi .org/10.1187/cbe.04-07-0045

[18] Kardash CM. Evaluation of undergraduate research experience: Perceptions of undergraduate interns and their faculty mentors. Journal of Educational Psychology. 2000; 92(1): 191. https ://doi .org/ 10.1037/0022-0663.92.1.191

[19] Asojo OA, et al. Summer Research Training Provides Effective Tools for Underrepresented Minorities to Obtain Doctoral Level Degrees. Journal of Racial and Ethnic Health Disparities. 2017; 1-8. https://doi.org/10.1007/s40615-016-0330-0

[20] Bauer KW, Bennett JS. Alumni perceptions used to assess undergraduate research experience. The Journal of Higher Education. 2003; 74(2): 210-230. https://doi.org/10.1353/jhe.2003.0011

[21] Barlow AE, Villarejo M. Making a difference for minorities: Evaluation of an educational enrichment program. Journal of Research in Science Teaching. 2004; 41(9): 861-881. https : //doi.org/10.1 002/tea. 20029

[22] Johnson MK, et al. Mentoring disadvantaged nursing students through technical writing workshops. Nurse Educator. 2007; 32(4): 168-172. PMid:17627209 https://doi.org/10.1097/01. NNE $.0000281087 .43088 . f 5$

[23] Derouin AL, et al. Use of Workshops to Develop Nurses' and Nursing Students' Writing Skills. The Journal of Continuing Education in Nursing. 2015; 46(8): 364-369. PMid:26247659 https: //doi.org/10.3928/00220124-20150721-03 